\title{
Results of small incision extracapsular cataract surgery using the anterior chamber maintainer without viscoelastic
}

Mark Wright, Hector Chawla, Alistair Adams

\begin{abstract}
Aims-To assess the efficacy of extracapsular cataract surgery using the anterior chamber maintainer (ACM) without the use of viscoelastic. To compare the effects of this surgical technique on non-diabetic and diabetic patients.
\end{abstract}

Methods-A prospective single armed clinical trial of 46 eyes in 46 patients undergoing cataract surgery using the ACM without viscoelastic. Patients were assessed preoperatively and at 3 weeks, 3 months, and 12 months postoperatively. The main outcome variables included visual acuity, surgically induced astigmatic change (SIAC), changes in endothelial cell density (ECD), and morphology affecting the central and superior regions of the cornea.

Results-Postoperatively, $56 \%$ and $70 \%$ of patients had unaided visual acuities of $6 / 12$ or better at 3 weeks and 3 months respectively. Even after excluding those patients with pre-existing maculopathy (including diabetic maculopathy), there remains a significant difference between the nondiabetic and diabetic groups in terms of the proportion of patients attaining an unaided visual acuity of $6 / 12$ or better at both 3 weeks $(p=0.003)$ and 3 months $(p=0.001)$. Three months postoperatively, the SIAC based upon the keratometric and refractive data was 1.1 dioptres (D) and $1.3 \mathrm{D}$ respectively. There was no statistically significant difference in the SIAC when the non-diabetic and diabetic groups were compared. The mean central and superior endothelial cell losses at 3 months postoperatively were $16 \%$ and $22 \%$ respectively and at 12 months postoperatively were $20 \%$ and $25 \%$ respectively. The diabetic group demonstrated greater endothelial cell losses and a more marked and protracted deviation of endothelial cell morphology from normality when compared with the non-diabetic group; however, the differences did not reach statistical significance.

Conclusions-The efficacy of small incision cataract surgery using the ACM in terms of visual outcome and induced astigmatism is comparable with the results obtained using other techniques that utilise a similar size of incision. However, in view of the magnitude and range of the endothelial cell losses associated with this technique the concurrent use of viscoelas- tic is suggested. There does not appear to be a statistically or clinically significant difference between non-diabetic and diabetic patients in terms of the magnitude of the endothelial cell losses or in the wound healing response in the 12 months after cataract surgery using the ACM.

(BrF Ophthalmol 1999;83:71-75)

The success of cataract surgery is now often measured by both doctors and patients in terms of the postoperative unaided visual acuity. Visual outcome continues to improve as small incision surgery evolves, with phacoemulsification emerging as the most popular technique. ${ }^{1}$ Blumenthal et $a l^{2-4}$ have described the use of the anterior chamber maintainer (ACM) allowing small incision cataract surgery to be performed without the use of viscoelastic agents or phacoemulsification. As far as we can ascertain, however, there have been no published reports assessing the effects of this particular technique of cataract surgery on the corneal endothelium.

The purpose of this study was to assess the efficacy and safety of the authors modifications ${ }^{5}$ of Blumenthal's "Mini-Nuc" technique and to compare its effects on both non-diabetic and diabetic patients.

\section{Patients and methods}

After informed written consent was obtained, 46 eyes from 46 subjects were entered into a single centre, single surgeon (HBC), single observer (MW), prospective single armed clinical trial of patients undergoing extracapsular cataract extraction (ECCE) and intraocular lens (IOL) implantation using the ACM. Viscoelastic substances were not used. Follow up was complete in 42 of 46 eyes (one patient died before his first postoperative visit, a further two died and one other patient was lost to follow up between the 3 and 12 month visits).

Exclusion criteria included previous intraocular surgery, significant corneal opacification, uveitis, glaucoma, or ocular hypertension. Of the study group as a whole, 17/46 (37\%) were diabetic, $13 / 17$ had non-proliferative diabetic retinopathy, and 4/17 had proliferative diabetic retinopathy.

The surgical technique has previously been described in detail. ${ }^{5}$ Essentially, paracentesis stab incisions were positioned at 2,4 , and 10 o'clock. Balanced salt solution containing adrenaline $(1 \mathrm{mg} / \mathrm{l})$ was continuously infused through a self retaining 20 gauge ACM (Visitec
Accepted for publication 11 September 1998 
No 5061) which had been inserted via the 4 o'clock paracentesis. A scleral three step tunnelled incision centred at the 12 o'clock position and of approximately $6 \mathrm{~mm}$ external diameter was fashioned using an angled crescent blade with the final entry into the anterior chamber made with a $3.2 \mathrm{~mm}$ keratome. A continuous curvilinear capsulorrhexis (with or without relaxing incisions) or beer can anterior capsulotomy was performed using a 23 gauge side cutting cystitome. The nucleus was first hydrodissected, then hydrodelineated and dislocated into the anterior chamber. The internal aspect of the wound was enlarged with the crescent blade and the nucleus was removed with a 25 gauge irrigating vectis. The residual soft lens matter was aspirated using a 23 gauge cortex extractor (Visitec No 5193) via either or both of the two paracentesis incisions. The wound was enlarged to allow easy insertion of a $6 \mathrm{~mm}$ three piece IOL with a polymethylmethacrylate optic and prolene haptics (J2B-62, Domilens SA, France) which was placed either in the capsular bag, or in the presence of a posterior capsular tear, in the sulcus. The wound was sutured using 10/0 mersilene in a single " $x$ " configuration, the conjunctiva was repositioned using diathermy and a subconjunctival injection of either cefuroxime or gentamicin was given. No patient received prophylactic IOP lowering measures and all were treated with topical betamethasone four times daily for a period of up to 8 weeks postoperatively.

Patients were assessed preoperatively and at 3 weeks, 3 months, and 12 months postoperatively. Preoperative and postoperative data collection included corneal endothelial cell density and morphology data from the central and superior (decentred by $3 \mathrm{~mm}$ ) regions of both the operated and unoperated (control) eyes, unaided and best corrected visual acuities (BCVA), refraction and keratometry, IOL centration, and posterior capsular opacification. All intraoperative and postoperative complications were noted. The endothelium was imaged using the Konan non-contact specular microscope model SP-8000 (Konan Medical, Nishinomiya, Japan) endothelial cell densities were determined using the cell centre method, the coefficient of variation (COV) in cell size and the percentage of hexagonal cells were automatically calculated. A mean number of 102 cells per image were analysed, satisfactory images were obtained in $96 \%$ of eyes imaged.

The SIAC was calculated using both the refractive and keratometric data from the 3 month visit using the method described by Holladay et al. ${ }^{6}$ Absolute endothelial cell counts (including apparent increases in endothelial cell density (ECD)) were used to calculate the percentage change in the ECD. From a statistical standpoint, overestimations and underestimations of ECD can be negated by using the actual values of the endothelial cell counts.

The differences between the diabetic and non-diabetic groups in terms of the visual outcome were analysed using the $\chi^{2}$ test. The intersession variability in the measurements of the ECD from the contralateral (control) eye were analysed using the ANOVA test. All other statistical analysis was performed using the Student's $t$ test, $\mathrm{p}$ values of $<0.05$ were considered to be statistically significant.

\section{Results}

The mean patient age was 72 years, $28 / 46$ $(61 \%)$ were female and $33 / 46(72 \%)$ of the patients had a BCVA of less than or equal to $6 / 24$ preoperatively.

VISUAL OUTCOME

At 3 weeks postoperatively, 24/43 (56\%) had unaided visual acuities of $6 / 12$ or better (one patient died before his 3 week visit and a further two patients were intentionally left with between 3 and 4 dioptres of ammetropia postoperatively and were therefore excluded). At 3 months postoperatively, 30/43 (70\%) had unaided visual acuities of $6 / 12$ or better (two patients required laser capsulotomy at 3/12 and were included). No patient required suture removal.

None of the patients (3/45) who had BCVAs of less than 6/12 suffered intraoperative or postoperative complications and all had incidental reasons for their poorer visual outcome; age related macular degeneration, macula involving retinoschisis and a combination of diabetic maculopathy and a supratemporal branch retinal vein occlusion, both of which were noted preoperatively.

There was no significant difference between the non-diabetic and diabetic groups in the proportion of patients attaining a BCVA of $6 / 12$ or better $(p=0.244)$. If, in addition to the two patients with deliberate postoperative ammetropia we also exclude the patients with pre-existing maculopathy (including diabetic maculopathy), there remains a significant difference between the two groups in terms of the proportion of patients attaining an unaided visual acuity of $6 / 12$ or better at both 3 weeks $(p=0.003)$ and 3 months $(p=0.001)$.

\section{SURGICALLY INDUCED ASTIGMATIC CHANGE}

(SIAC)

Three months postoperatively, the mean SIAC based upon the keratometric data $(n=44)$ was $1.1 \mathrm{D}$ (SD 0.6, range 0.1-2.7). When the refractive data $(n=35)$ were analysed, the corresponding figures are $1.3 \mathrm{D}(0.8,0.1-3.0)$. There was no statistically significant difference in the SIAC when the keratometric or refractive data were compared $(\mathrm{p}=0.288)$. There was no statistically significant difference between the non-diabetic and diabetic groups in the SIAC for both the keratometric $(p=0.127)$ and refractive data $(p=0.400)$.

\section{SURGICALLY INDUCED ENDOTHELIAL CHANGE} (SIEC)

Analysis of the endothelial data from the central region of the contralateral (control) eye was used to validate the repeatability of the method of measurement. The mean central ECD of the control eyes which did not undergo surgery during the study period $(n=34)$ was 2185 (SD 545) cells $/ \mathrm{mm}^{2}$ (range 
Table 1 Mean (SD) (range) of the change in the central endothelial cell density (cells/mm²)

\begin{tabular}{|c|c|c|c|}
\hline & Overall $(n=46)$ & Non-diabetic $(n=29)$ & Diabetic $(n=17)$ \\
\hline $\begin{array}{l}\text { Preoperative } \\
3 \text { months postoperatively } \\
12 \text { months postoperatively }\end{array}$ & $\begin{array}{l}2430(374)(1683-3184) \\
2072(577)(669-3460) \\
1965(607)(626-3311)\end{array}$ & $\begin{array}{l}2432(401)(1683-3184) \mathrm{p}=0.953 \\
2122(611)(669-3460) \mathrm{p}=0.443 \\
2019(638)(626-3311) \mathrm{p}=0.395\end{array}$ & $\begin{array}{l}2426(336)(1915-3154) \\
1982(517)(1078-2801) \\
1845(534)(1114-2724)\end{array}$ \\
\hline \multicolumn{4}{|c|}{$\begin{array}{l}\mathrm{p}=\text { unpaired two tailed Student's } t \text { test statistic of non-diabetic } v \text { diabetic endothelial cell losses. Age matched normal value of ECD } \\
\text { is }>2570 \text { cells } / \mathrm{mm}^{2}{ }^{8}\end{array}$} \\
\hline \multicolumn{4}{|c|}{$\begin{array}{l}\text { Table } 2 \text { Mean (SD) (range) of the change in the central endothelial cell density (ECD) (expressed as a percentage of the } \\
\text { preoperative ECD) }\end{array}$} \\
\hline & Overall $(n=46)$ & Non-diabetic $(n=29)$ & Diabetic $(n=17)$ \\
\hline $\begin{array}{l}3 \text { months postoperatively } \\
12 \text { months postoperatively }\end{array}$ & $\begin{array}{l}84(17)(36-113) \\
80(19)(33-108)\end{array}$ & $\begin{array}{l}86(17)(36-113) \mathrm{p}=0.334 \\
82(20)(33-108) \mathrm{p}=0.327\end{array}$ & $\begin{array}{l}81(18)(42-111) \\
75(17)(43-108)\end{array}$ \\
\hline \multicolumn{4}{|c|}{$\mathrm{p}=$ Student's $t$ test statistic of non-diabetic $v$ diabetic endothelial cell losses. } \\
\hline \multicolumn{4}{|c|}{ Table 3 Mean (SD) (range) of the change in superior endothelial cell density (cells $/ \mathrm{mm}^{2}$ ) } \\
\hline & Overall $(n=46)$ & Non-diabetic $(n=29)$ & Diabetic $(n=17)$ \\
\hline $\begin{array}{l}\text { Preoperative } \\
3 \text { months postoperatively } \\
12 \text { months postoperatively }\end{array}$ & $\begin{array}{l}2444(417)(1694-3196) \\
1937(726)(564-3558) \\
1846(742)(585-3484)\end{array}$ & $\begin{array}{l}2469(421)(1722-3196) \mathrm{p}=0.799 \\
1951(779)(564-3558) \mathrm{p}=0.866 \\
1936(770)(585-3484) \mathrm{p}=0.255\end{array}$ & $\begin{array}{l}2447(372)(1694-3152) \\
1907(631)(957-3125) \\
1650(663)(850-3046)\end{array}$ \\
\hline
\end{tabular}

Table 4 Mean (SD) (range) of the change in superior endothelial cell density (ECD) (expressed as a percentage of the preoperative ECD)

\begin{tabular}{llll}
\hline & Overall $(n=46)$ & Non-diabetic $(n=29)$ & Diabetic $(n=17)$ \\
\hline 3 months postoperatively & $78(25)(25-124)$ & $79(26)(25-116) \mathrm{p}=0.664$ & $76(23)(44-124)$ \\
12 months postoperatively & $75(26)(30-120)$ & $78(26)(30-118) \mathrm{p}=0.245$ & $68(25)(38-120)$ \\
\hline
\end{tabular}

$\mathrm{p}=$ Student's $t$ test statistic of non-diabetic $v$ diabetic endothelial cell losses.

992-3236) “preoperatively"; 2169 (536) cells/ $\mathrm{mm}^{2}(912-3125)$ at 3 months; and 2179 (564) cells $/ \mathrm{mm}^{2}(977-3067)$ at 12 months "postoperatively". There was no significant difference when the "preoperative", 3, and 12 months "postoperative" measurements were analysed $(\mathrm{p}=0.0001)$.

The data from the operated eyes are depicted in tabular form. The SIEC from the central region of the cornea is shown in Tables 1 and 2. The SIEC from the superior region of the cornea is shown in Tables 3 and 4 . The surgically induced morphological changes in the endothelium were described by the COV in cell size and the percentage of hexagonal cells. The changes in the COV in cell size from the

Table 5 Mean (SD) of the coefficient of variation (COV) in cell size from the central (c) and superior regions of the cornea

\begin{tabular}{llll}
\hline & Overall $(n=46)$ & Non-diabetic $(n=29)$ & Diabetic $(n=17)$ \\
\hline Preoperative & $0.31(0.06)(\mathrm{c})$ & $0.31(0.06)(\mathrm{c})$ & $0.32(0.07)(\mathrm{c})$ \\
& $0.32(0.04)$ & $0.32(0.06)$ & $0.34(0.08)$ \\
3 months postoperatively & $0.38(0.07)(\mathrm{c})$ & $0.37(0.07)(\mathrm{c})$ & $0.39(0.07)(\mathrm{c})$ \\
& $0.37(0.08)(\mathrm{c})$ & $0.36(0.08)(\mathrm{c})$ & $0.38(0.08)$ \\
12 months postoperatively & $0.35(0.08)(\mathrm{c})$ & $0.34(0.08)(\mathrm{c})$ & $0.36(0.07)(\mathrm{c})$ \\
& $0.34(0.08)$ & $0.33(0.07)$ & $0.36(0.08)$ \\
\hline
\end{tabular}

There were no statistically significant differences between the non-diabetic and diabetic groups when the changes in the COV in cell size were analysed.

Age matched normal value of COV in cell size $<0.33 .^{8}$

Table 6 Mean (SD) of the percentage of hexagonal cells from the central (c) and superior regions of the cornea

\begin{tabular}{llll}
\hline & Overall $(n=46)$ & Non-diabetic $(n=29)$ & Diabetic $(n=17)$ \\
\hline Preoperative & $64(10)(\mathrm{c})$ & $66(9)(\mathrm{c})$ & $61(12)(\mathrm{c})$ \\
3 months postoperatively & $64(8)$ & $66(9)$ & $60(9)$ \\
& $56(9)(\mathrm{c})$ & $55(9)(\mathrm{c})$ & $56(9)(\mathrm{c})$ \\
12 months postoperatively & $59(9)(\mathrm{c})$ & $54(9)$ & $57(9)$ \\
& $60(9)$ & $61(8)(\mathrm{c})$ & $57(10)(\mathrm{c})$ \\
\end{tabular}

There were no statistically significant differences between the non-diabetic and diabetic groups when the changes in the percentage of hexagonal cells were analysed.

Age matched normal value of $\mathrm{COV}$ in cell size $>60 \%{ }^{8}$ central (c) and superior regions of the cornea are shown in Table 5 . The change in the percentage of hexagonal cells from the central (c) and superior regions of the cornea is shown in Table 6.

INTRAOCULAR LENS POSITION

Patients were dilated at the 3 month visit when the position of the IOL was confirmed: $31 / 45$ $(69 \%)$ of the IOLs were confirmed to be in the capsular bag, 13/45 (29\%) were sulcus fixated, $1 / 45(2 \%)$ was half in half out.

POSTERIOR CAPSULAR OPACIFICATION

Significant posterior capsular thickening (requiring laser capsulotomy) occurred in $2 / 45$ $(4 \%)$ of cases at 3 months and a further $1 / 42$ $(2 \%)$ at 12 months postoperatively.

\section{COMPLICATIONS}

Surgery was uneventful in $42 / 46(91 \%)$ and capsular rupture and/or vitreous loss occurred in $4 / 46(9 \%)$ of cases. The IOP was measured between 16 and 24 hours postoperatively; the mean rise in IOP was $6 \mathrm{~mm} \mathrm{Hg}$ with the highest IOP measured at $45 \mathrm{~mm} \mathrm{Hg}$ (following uncomplicated surgery). No patient had raised IOP at either of the two postoperative visits. Superior iris atrophy was observed in 5/46 $(11 \%)$ of patients postoperatively.

\section{Discussion}

VISUAL OUTCOME AND REFRACTIVE CHANGE The proportion of the patients in this study with uncorrected visual acuities of $6 / 12$ or better at 3 weeks and 3 months after surgery were $56 \%$ and $70 \%$ respectively. Steinart et al ${ }^{9}$ reported that following phacoemulsification using incisions of 4 and $6.5 \mathrm{~mm}, 62 \%$ and $57 \%$ of patients at 5 weeks and $70 \%$ and $67 \%$ of 
patients at 3 months had uncorrected visual acuities of $6 / 12$ or better. The induced astigmatic cylinder in our study was $1.1 \mathrm{D}$ which is again comparable with Steinart's ${ }^{9}$ figures (based upon keratometric data) of $0.82 \mathrm{D}$ and $1.03 \mathrm{D}$.

When the visual outcome of the diabetic and non-diabetic groups are compared, the similarity between the two groups in terms of the BCVA is explained by the low prevalence of diabetic maculopathy in our study group; however, we cannot offer a satisfactory explanation for the disparity observed in the unaided visual acuity.

CHANGES IN ENDOTHELIAL CELL DENSITY AND MORPHOLOGY

The mean intersession variability in the measurements of the ECDs of the unoperated (control) eye was $<1 \%$ indicating a high degree of repeatability which is in keeping with the results of other studies. ${ }^{10}$ There was no significant regional variation (central $v$ superior) in the mean ECD preoperatively $(\mathrm{p}=0.799)$. Postoperatively, all eyes demonstrated vertical endothelial cell disparity at both the 3 and 12 month visits with greater endothelial losses found superiorly towards the site of the incision. The mean central and superior endothelial cell losses at 3 months postoperatively were $16 \%$ and $22 \%$ respectively and at 12 months postoperatively were $20 \%$ and $25 \%$ respectively. Depending upon the technique of phacoemulsification employed and the type of viscoelastic used the reported mean central endothelial cell losses range from $4 \%{ }^{11}$ to $14 \%{ }^{12}$ at 3 months postoperatively. Similarly, the mean superior endothelial cell losses range from $8 \%$ to $16 \%$ between 12 and 24 months postoperatively. ${ }^{13}$ Modern extracapsular surgery using viscoelastics results in central endothelial cell losses of approximately $15 \%$ at 3 months postoperatively. ${ }^{14} 15$

The range in the magnitude of the endothelial cell losses was considerable, with five patients $(11 \%)$, despite having undergone uncomplicated surgery demonstrating endothelial cell losses which were greater than twice the mean. These patients did not differ from the study group as a whole in terms of the prevalence of diabetes.

The mean central endothelial cell losses (combined 3 and 12 month data) of the group of four patients who had posterior capsular tears and/or vitreous loss was $14 \%$ which compares favourably with the equivalent figure of $18 \%$ for the group undergoing uncomplicated surgery. The mean superior endothelial cell losses for the same two groups were $22 \%$ and $23 \%$ respectively. The mean central endothelial cell losses (combined 3 and 12 month data) of the group of five patients who were noted postoperatively to have superior iris atrophy was $34 \%$ compared with cell losses of $16 \%$ in those patients in whom the iris had a normal appearance $(p=0.004)$. The mean superior endothelial losses for these two groups was $49 \%$ and $21 \%$ respectively $(p=0.001)$. The association of superior iris atrophy and excessive endothelial cell losses is likely to reflect an increased degree of difficulty in removal of the nucleus which in turn is related to its density and/or size.

We included diabetics in our study population to permit a comparative analysis of the effects of this technique of cataract surgery on the endothelium of diabetics and nondiabetics. Patients with diabetes have often been excluded from clinical trials that have attempted to assess the deleterious effects of cataract surgery on the corneal endothelium because of the assumption that the diabetic endothelium has an increased susceptibility to damage during surgery. ${ }^{11}{ }^{16}$ The central and superior mean ECD losses at both 3 and 12 months postoperatively were consistently higher in the diabetic patients; however, the differences did not reach statistical significance. These results are in agreement with the findings of other investigators. ${ }^{15}{ }^{17}$ Endothelial cell morphology data provide a more sensitive indication of endothelial cell damage than do cell density measurements alone. ${ }^{18}$ The COV in cell size and the percentage of hexagonal cells are quantifiable indicators of variation in cell size (polymegathism) and cell shape (pleomorphism). Increases in the COV in cell size and/or decreases in the percentage of hexagons indicate some form of endothelial injury. Analysis of the endothelial cell morphology data demonstrated a similar pattern to the ECD data, with the diabetic group having a larger COV in cell size and a smaller percentage of hexagons without the differences between the groups reaching statistical significance.

Schultz et $a l^{19}$ reported that the naturally occurring rate of endothelial cell loss and prevalence of morphological abnormalities in patients with type I diabetes is greater than age matched patients with type II diabetes. The numbers of patients in each of the diabetic subgroups in our study precluded the investigation of the relation between the severity and/or duration of the patients' diabetes and the magnitude of the endothelial cell losses associated with cataract surgery.

What is the clinical significance of endothelial cell losses associated with the use of the ACM which are higher than those reported using other techniques? The average annual endothelial cell loss rate in healthy unoperated eyes is around $0.5 \% .{ }^{8}$ The chronic exponential endothelial cell loss rate $5-10$ years after cataract surgery ranges from $1.1 \%{ }^{20}$ to $2.5 \%^{21}$ per annum. While accepting that the endothelial mosaic of the diabetic group has not yet stabilised, it seems reasonable to assume that after the first postoperative year our patients would continue to lose endothelial cells at no more than $2.5 \%$ per annum. As our mean 12 month postoperative ECD was 1965 cells $/ \mathrm{mm}^{2}$, we can therefore calculate that it would take approximately 50 years before the mean cell density decreased to 500 cells $/ \mathrm{mm}^{2}$, the level at which corneal decompensation was found to be imminent by Bates et al. ${ }^{22}$ 
Conclusions and recommendations

The overall results of this clinical trial demonstrate that the efficacy of small incision cataract surgery using the ACM in terms of visual outcome and induced astigmatism is comparable with the results obtained using other techniques that utilise a similar size of incision. The magnitude and range of the endothelial cell losses associated with this technique are, however, significantly greater than those described following phacoemulsification. It has been shown that the use of viscoelastic can reduce the endothelial losses associated with cataract surgery by up to $50 \% .^{23}$ We would therefore suggest that small incision extracapsular cataract surgery using the ACM is an effective and safe technique, however, in order to minimise endothelial cell losses we would suggest the concurrent use of viscoelastic.

There does not appear to be a statistically or clinically significant difference between nondiabetics and diabetics in the magnitude of the endothelial cell losses or in the wound healing response in the 12 months after cataract surgery using the ACM.

1 Schein OD, Bass EB, Sharkey $\mathrm{P}$, et al. Cataract surgical techniques. Preferences and underlying beliefs. Arch Ophthalmol 1995;113:1108-12.

2 Blumenthal M, Assia E, Schochot Y. Lens anatomical principles and their technical implications in cataract surgery. Part I: The lens capsule. I Cataract Refract Surg 1991;17:205-10

3 Blumenthal M, Assia E, Neuman D. Lens anatomical principles and their technical implications in cataract surgery. Part II: The lens nucleus. 7 Cataract Refract Surg 1991;17: 211-17.

4 Blumenthal M, Ashkenazi I, Assia E, et al. Small incision manual extracapsular cataract extraction using selective hydrodissection. Ophthalmic Surg 1992;23:699-701.

5 Chawla HB, Adams AD. Use of the anterior chamber maintainer in anterior segment surgery. F Cataract Refract Surg 1996;22:172-7.

6 Holladay JT, Cravy TV, Koch DD. Calculating the surgically induced refractive change following ocular surgery. F Cataract Refractive Surg 1992;18:429-43.
7 Hayashi K. Calculating endothelial cell loss. 7 Cataract Refractive Surg 1997;23:6.

8 Yee RW, Matsuda M, Schultz RO, et al. Changes in the normal corneal endothelial cellular pattern as a function of age. Curr Eye Res 1985;4:671-8.

9 Steinart RF, Brint SF, White SM, et al. Astigmatism after small incision cataract surgery. Ophthalmology 1991;98: $417-23$.

10 Landesz M, Siertsema JV, Van Rij G. Comparative study of three semiautomated specular microscopes. F Cataract Refract Surg 1995;21:409-16.

11 Hayashi K, Hayashi H, Nakao F, et al. Corneal endothelial cell loss in phacoemulsification surgery with silicone intraocular lens implantation. F Cataract Refract Surg 1996; 22:743-7.

12 Koch DD, Liu JF, Glasser DB, et al. A comparison of corneal endothelial changes after use of healon or viscoat during phacoemulsification. Am 7 Ophthalmol 1993;115: 188-201.

13 Lavery KT, McDermott ML, Ernest PH, et al. Endothelial loss after $4 \mathrm{~mm}$ cataract surgery. F Cataract Refract Surg 1995;21:305-8.

14 Szweda E, Donotek-Barecka Z, Lesiewska-Junk H. Corneal endothelium after cataract surgery. Klinica Oczna 1994;96: $60-2$.

15 Furuse N, Hayaska S, Yamamoto Y, et al. Corneal endothelial changes after posterior chamber intraocular lens implantation in patients with or without diabetes mellitus. Br F Ophthalmol 1990;74:258-60.

16 Schultz RO, Glasser DB, Matsuda M, et al. Response of the corneal endothelium to cataract surgery. Arch Ophthalmol 1986;104:1164-9.

17 Wojciechowska R, Bolek S, Janiec S. Corneal endothelium in patients with diabetes after extracapsular cataract in patients with diabetes after extracapsular cataract posterior chamber. Klinica Oczna 1995;97:221-2

18 Rao GN, Shaw EL, Arthur EJ, et al. Endothelial cell morphology and corneal deturgescence. Ann Ophthalmol 1979;11:885-99.

19 Schultz RO, Matsuda M, Yee RW, et al. Corneal endothelial changes in type I and type II diabetes mellitus. Am f Ophthalmol 1984;98:397-410.

20 Numa A, Nakamura J, Takashima M, et al. Long term corneal endothelial changes after intraocular lens implantation. Anterior vs posterior chamber lenses. Fpn f Ophthalmol 1993;37:78-87.

21 Bourne WM, Nelson LR, Hodge DO. Continued endothelial cell loss ten years after lens implantation. Ophthalmology 1994;101:1014-22.

22 Bates AK, Cheng H, Hiorns RW. Pseudophakic bullous keratopathy: relationship with endothelial cell density and use of a predictive cell loss model. A preliminary report. Curr Eye Res 1986;5:363-6.

23 Alpar J. Endothelial cell loss in different non-automated extracapsular nuclear evacuation techniques and the role of sodium hyaluronate. Ophthalmic Surg 1986;17:719-23. 